\title{
RE-DESAIN KANTOR SEKRETARIAT DAN RUANG PUBLIK RW.08, KELURAHAN TOMANG, KECAMATAN GROGOL PETAMBURAN, JAKARTA BARAT
}

\author{
Nafiah Solikhah ${ }^{1}$, Yunita Ardianti S. ${ }^{2}$, Sintia Dewi W. ${ }^{3}$ \\ ${ }^{1}$ Prodi S1 Arsitektur, Universitas Tarumanagara Jakarta \\ Email: nafiahs@ft.untar.ac.id \\ ${ }^{2}$ Prodi S1 Arsitektur, Universitas Tarumanagara Jakarta \\ Email: sintiadewe@gmail.com \\ ${ }^{3}$ Prodi S1 Arsitektur, Universitas Tarumanagara Jakarta \\ Email: yunita4architect@gmail.com
}

\begin{abstract}
ABSTRAK
Sebagai salah satu fasilitas umum pemerintahan, Kantor $R W$ memiliki peranan yang cukup signifikan dalam mewadahi aktivitas sosial masyarakat. Berdasarkan hasil tinjauan lapangan, kantor sekretariat RW.08 Kelurahan Tomang, Kecamatan Grogol Petamburan, Jakarta Barat yang berada di dekat kampus 1 UNTAR memiliki peranan untuk mewadahi beragam kegiatan, antara lain: kegiatan Karang Taruna, Posyandu, Pospindu, Sekretariat Jumantik. Sedangkan Ruang Publik yang berada dalam satu tapak dengan kantor sekretariat RW.08 saat ini masih kurang terawat dan tidak terencana dengan baik. Berdasarkan permasalahan mitra, maka solusi yang Tim ajukan adalah kegiatan PKM untuk Re-Desain Kantor Sekretariat dan Ruang Publik RW.08, Kelurahan Tomang, Kecamatan Grogol Petamburan, Jakarta Barat. Pelaksanaan kegiatan PKM menggunakan metode partisipasi mitra. Adapun tahapan pelaksanaan yaitu: Perencanaan Desain, Konsep Desain dan Desain. Konsep Desain yang diusulkan adalah: Usulan Desain Kantor Sekretariat RW yang Mencerminkan Karakter Arsitektur Betawi, pengadaan Taman Refleksi dan Relaksasi, pewadahan aktivitas Bank Sampah, usulan Taman Taman Tanaman Obat Keluarga (TOGA) dan Vertikultur. Kantor sekretariat $R W$ sebaiknya mampu menjadi fasilitas penunjang yang berfungsi untuk menyelenggarakan dan mengembangkan kehidupan ekonomi, sosial dan budaya, dan memperkuat karakter wajah kota Jakarta serta menyediakan fasilitas yang memadai dan layak secara fungsional dan estetika. Dalam melakukan re-desain kantor publik, harus mengacu pada standar (SNI, Perda, dll) serta harus ada diskusi aktif dengan mitra.
\end{abstract}

Kata kunci: Re-Desain, Ruang Publik, Kantor Sekretariat RW

\section{PENDAHULUAN}

Kantor Sekretariat dan Ruang Publik RW. 08, Kelurahan Tomang, Kecamatan Grogol berada di Jalan Tawakal Ujung Raya RW.08, Kelurahan Tomang, Kecamatan Grogol Petamburan, Jakarta Barat atau sisi timur Universitas Tarumanagara Kampus I dengan jarak 450 meter (Gambar 1).

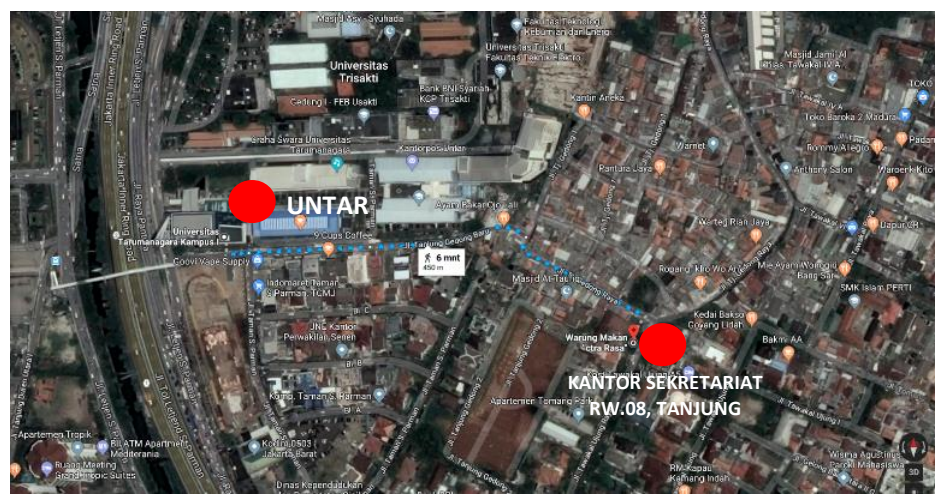

Gambar 1. Lokasi Mitra (Sumber: https://www.google.co.id/maps) 
Sasaran PKM berada di tengah-tengah permukiman penduduk. Berdasarkan hasil tinjauan lapangan, kantor sekretariat RW.08 memiliki peranan untuk mewadahi beragam kegiatan, antara lain: kegiatan Karang Taruna, Posyandu, Pospindu, Sekretariat Jumantik. Sedangkan Ruang Publik yang berada dalam satu tapak dengan kantor sekretariat RW.08 saat ini masih kurang terawat dan tidak terencana dengan baik. Dengan menata ulang kantor sekretariat dan ruang publik RW. 08, maka diharapkan dapat mengoptimalkan fungsinya untuk mewadahi beragam aktivitas.

\section{Analisis Situasi}

Berdasarkan SNI 03-1733-2004 bahwa sarana lingkungan adalah fasilitas penunjang yang berfungsi untuk menyelenggarakan dan mengembangkan kehidupan ekonomi, sosial dan budaya.

Yang termasuk dalam sarana pemerintahan dan pelayanan umum adalah:

- kantor-kantor pelayanan/administrasi pemerintahan dan administrasi kependudukan;

- kantor pelayanan utilitas umum dan jasa; seperti layanan air bersih (PAM), listrik (PLN), telepon, dan pos; serta

- pos-pos pelayanan keamanan dan keselamatan; seperti pos keamanan dan pos pemadam kebakaran

Berdasarkan perda Provinsi DKI Jakarta No. 1 Tahun 2012 tentang Rencana Tata Ruang Wilayah 2030 Pasal 6 ayat 9, untuk menciptakan budaya kota Jakarta yang setara dengan kota-kota besar di negara maju. Aktivitas sosial dapat diartikan sebagai kegiatan yang membutuhkan kehadiran orang lain (Zhang dan Lawson, 2009). Kegiatan ini dapat berupa perbincangan santai di pinggir jalan, bertatap muka maupun kegiatan anak-anak bermain di taman kota. Berdasarkan analisis situasi tersebut, sebagai salah satu fasilitas umum pemerintahan, Kantor RW memiliki peranan yang cukup signifikan dalam mewadahi aktivitas sosial masyarakat. Berdasarkan beberapa kebijakan yang telah dikeluarkan oleh Pemprov. DKI Jakarta, maka hendaknya desain dari fasilitas umum pemerintahan memperkuat karakter wajah kota Jakarta dan menyediakan fasilitas yang memadai dan layak secara fungsional dan estetika.

\section{Permasalahan Mitra}

Berdasarkan kunjungan awal Tim ke lokasi serta wawancara dengan Bapak M. Yusuf selaku ketua RW. 08, Kelurahan Tomang, Kecamatan Grogol Petamburan terdapat beberapa permasalahan yang dihadapi oleh Mitra. Pertama, bangunan kantor sekretariat RW kurang mencerminkan karakter wajah kota Jakarta. Penataan tata ruang belum bisa optimal dan fleksibel untuk mewadahi beragam aktivitas (Karang Taruna, Posyandu, Pospindu, Jumantik, dll).

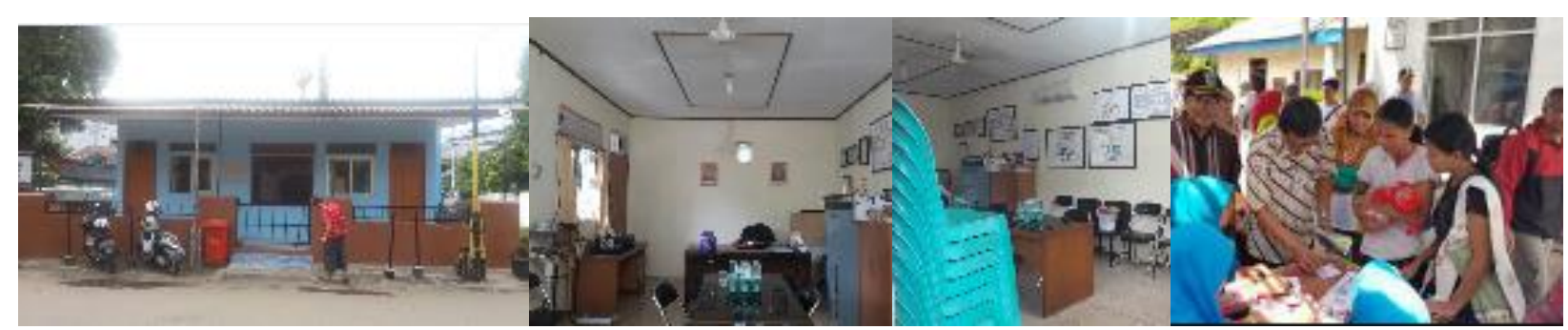

Gambar 2. Eksisting Kantor Sekretariat (Sumber: Survei, 2018)

Kedua, Taman kurang tidak dimanfaatkan secara optimal dan justru berubah menjadi gudang penyimpanan. Salah satu usulan yang disampaikan oleh mitra adalah perencanaan taman Toga (tanaman obat keluarga), taman refleksi dan kegiatan bank sampah. 

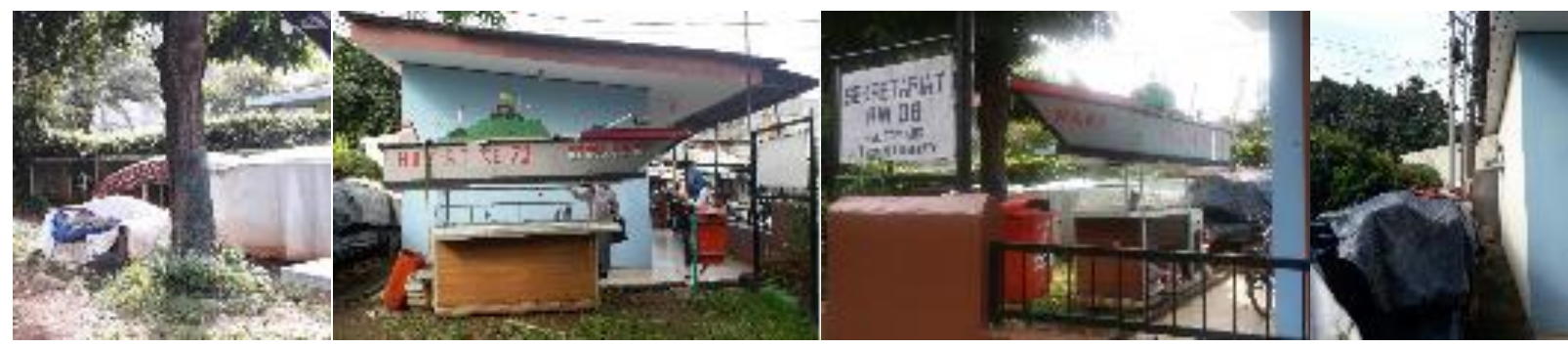

Gambar 3. Taman menjadi Gudang Penyimpanan (Sumber: Survei, 2018)

Ketiga, Ruang Publik yang ada saat ini seharusnya bisa menjadi ruang publik dan dimanfaatkan untuk beragam aktivitas. Salah satu permasalahan yang dihadapi oleh lingkungan adalah sering diadakannya hajatan di jalan sehingga mengganggu sirkulasi kendaraan bermotor. Usulan mitra adalah jika memungkinkan ruang publik bisa sekaligus menjadi solusi pewadahan kegiatan dengan peserta sekitar 200 orang (rapat warga, senam warga, acara 17 Agustus, dll).

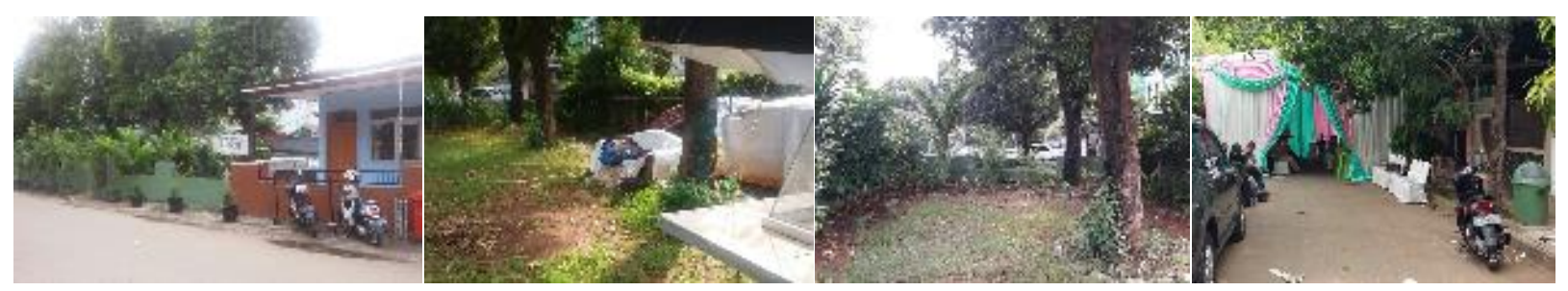

Gambar 4. Permasalahan kurang optimalnya fungsi area hijau kawasan

(Sumber: Survei, 2018)

Program pengabdian kepada masyarakat dengan topik "Re-Desain Kantor Sekretariat dan Ruang Publik RW.08, Kelurahan Tomang, Kecamatan Grogol Petamburan, Jakarta Barat" merupakan topik yang sesuai dengan misi dari DPPM UNTAR untuk memenuhi kebutuhan masyarakat. Selain itu mengingat lokasi mitra sasaran berada di sekitar kampus 1 UNTAR maka kegiatan PKM ini menjadi salah satu wujud nyata kontribusi UNTAR terhadap lingkungan sekitar.

Berdasarkan permasalahan mitra, maka solusi yang Tim ajukan adalah kegiatan PKM untuk ReDesain Kantor Sekretariat dan Ruang Publik RW.08, Kelurahan Tomang, Kecamatan Grogol Petamburan, Jakarta Barat. Batasan area perencanaan adalah kantor sekretariat dan area publik berupa taman yang berada dalam satu tapak kantor sekretariat. Hasil re-desain berupa gambar denah, tampak, potongan, dan perspektif 3 dimensi serta animasi yang nantinya menjadi usulan bagi mitra. Target luaran kegiatan PKM adalah artikel ilmiah yang siap dipublikasikan dalam seminar dan/ prosiding nasional/jurnal nasional.

\section{METODE PELAKSANAAN}

Kegiatan PKM menggunakan metode partisipasi mitra. Adapun tahapan pelaksanaan yaitu:

\section{Perencanaan Desain}

Pada awal dilakukan kajian literatur terkait kriteria fasilitas umum pemerintahan Pemerintah Provinsi DKI Jakarta serta kajian pada studi kasus yang sejenis sebagai referensi. Selanjutnya dilakukan proses pengukuran dan dokumentasi lokasi serta wawancara dengan perwakilan Mitra. Luaran tahap perencanaan desain adalah usulan pewadahan aktivitas sesuai dengan kriteria fasilitas umum pemerintahan berupa draft desain. 


\section{Konsep Desain}

Dari usulan desain yang telah mendapatkan masukan dari mitra, selanjutnya dibuat konsep desain secara arsitektural dan pewadahan beberapa aktivitas di pos RW. 08.

\section{Desain}

Tahapan akhir dari kegiatan PKM adalah proses desain. Luaran tahap ini adalah:

- Gambar 2 Dimensi : denah, tampak, potongan, dan detail arsitektur

Gambar 2 dimensi selain memberikan keterangan bentuk dan dimensi juga akan memberikan keterangan posisi dan jenis tanamannya

- Gambar 3 Dimensi : Gambar perspektif dari beberapa sudut

\section{HASIL DAN PEMBAHASAN}

\section{Proses Perencanaan Desain}

Tahap awal perencanaan dimulai dari diskusi tim PKM UNTAR dengan pihak mitra yang diwakili oleh Bapak M.Yusuf selaku ketua RW. 08. Adapun hasil diskusi dengan mitra antara lain:

- Mitra mengusulkan beberapa program kegiatan bersama yang nantinya dapat diwadahi sesuai dengan kebutuhan masyarakat, seperti: bank sampah, taman refleksi, taman bermain anak, TOGA, dll.

- Tim PKM Untar mengusulkan penataan kantor sekretariat RW 08 dan ruang rublik berdasarkan SNI 03-1733-2004 dan Perda Provinsi DKI Jakarta No. 1 Tahun 2012 dimana kantor sekretariat dan ruang publik hendaknya menjadi fasilitas penunjang yang berfungsi untuk menyelenggarakan dan mengembangkan kehidupan ekonomi, sosial dan budaya, dan memperkuat karakter wajah kota Jakarta serta menyediakan fasilitas yang memadai dan layak secara

- Selanjutnya Tim melakukan diskusi internal untuk mengumpulkan kajian literatur yang menunjang perencanaan konsep desain. Dari proses diskusi internal Tim yang mempertimbangkan permintaan Mitra maka dihasilkan usulan konsep desain awal yang mewadahi beberapa aktivitas, antara lain: tanaman obat keluarga, taman refleksi, vertikultur, fasilitas sosial, konsep betawi pada fasad bangunan kantor sekretariat RW dan pemindahan bak pemilahan sampah ke area yang agak jauh dari kantor sekretariat RW.

- Beberapa usulan desain tersebut selanjutnya didiskusikan kembali dengan ketua RW. Secara umum konsep usulan desain diterima oleh Ketua RW. Namun,ada beberapa catatan penting mengenai posisi Tanaman Obat Keluarga (TOGA) agar dikelompokkan sesuai dengan jenis tanamannya.

Usulan desain awal digambarkan dengan gambar sketsa perspektif dan site plan dimana sudah direncakan penempatan posisi bank sampah, taman refleksi, vertikultur, TOGA, dan rak penyimpanan barang (Gambar 5). 


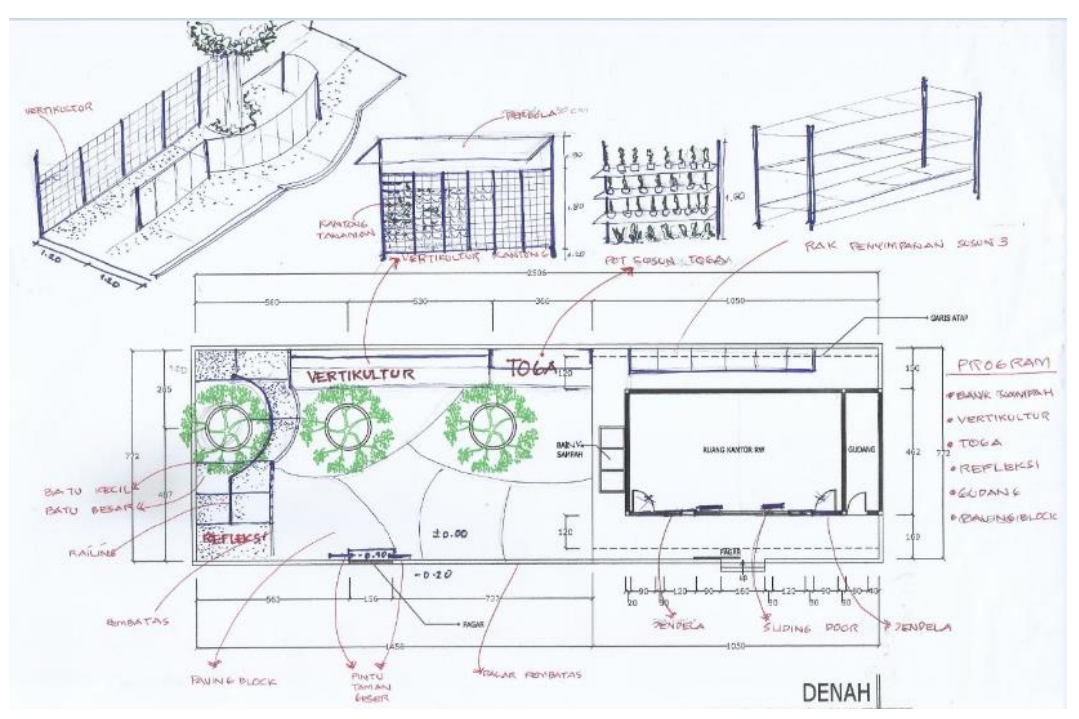

Gambar 5. Perspektif dan Denah Rencana Usulan Desain (Sumber: Survei, Mei 2018)

\section{Konsep Desain}

Dari usulan desain yang telah mendapatkan masukan dari mitra, selanjutnya dibuat konsep desain dengan produk akhir berupa gambar denah, tampak, potongan, dan perspektif. Adapun konsep desain yang direncanakan adalah:

- Mengusung nuansa betawi (berdasarkan Perda Provinsi DKI Jakarta No. 1 Tahun 2012, Pasal 6): Fasad depan kantor RW mempunyai karakter rumah Betawi

- Manfaat dari ruang publik untuk mewadahi beberapa aktivitas (berdasarkan SNI 03-1733-2004)

: Area publik RW dimanfaatkan untuk taman refleksi, TOGA, bank sampah, dan vertikultur

\section{a. Usulan Desain Kantor Sekretariat RW yang Mencerminkan Karakter Jakarta}

Rumah Betawi merupakan bangunan tradisional masyarakat Jakarta. Fasad rumah Betawi mempunyai fasad yang simetris dengan pintu ganda di tengah dan jendela di kanan kirinya (Gambar 6). Papan lisplank atap menggunakan hiasan ukiran kayu (Gambar 6). Rencana desain fasad yang diusulkan adalah membuat pintu ganda di tengah dan jendela di kanan kirinya (Gambar 7). Papan lisplang atap juga menggunakan ukiran kayu berkarakter rumah Betawi (Gambar 7). Adanya pintu ganda di tengah memudahkan sirkulasi pengunjung saat kantor RW mempunyai acara hajatan atau acara resmi.

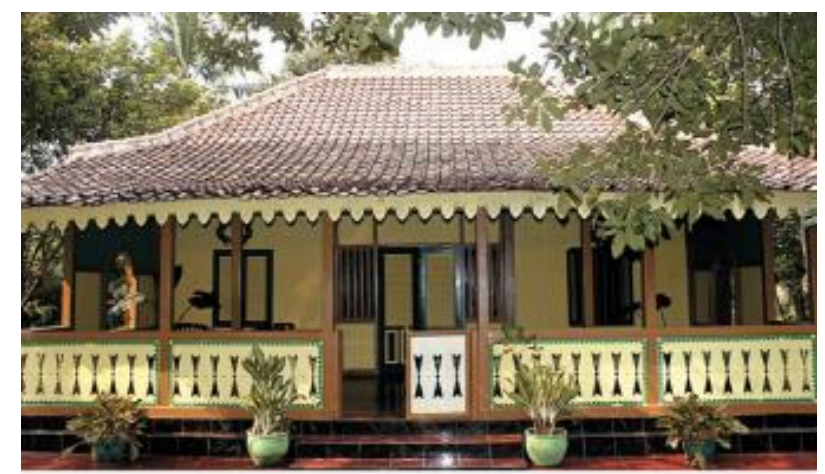

Gambar 6. Fasad Rumah Betawi

(Sumber: https://ekbis.sindonews.com; diakses tanggal 12 Februari 2018) 

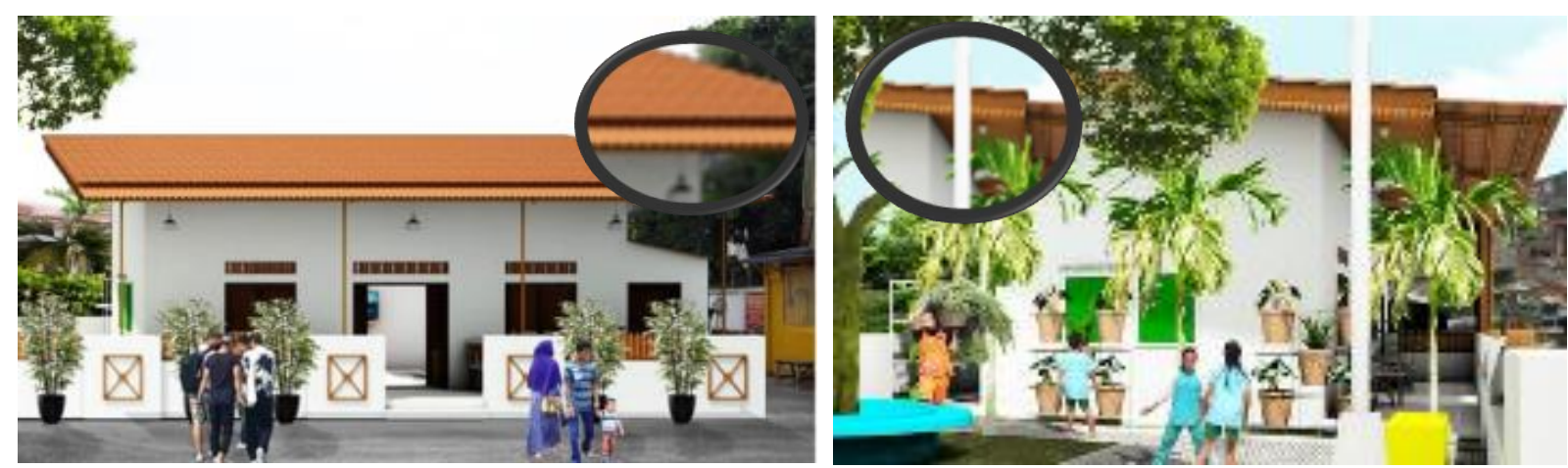

Gambar 7. Desain Tampak Depan dan Tampak Samping Kantor Sekretariat RW

(Sumber: Tim PKM, 2018)

\section{b. Taman Refleksi dan Relaksasi}

Dengan adanya taman refleksi dan relaksasi tersebut diharapkan area hijau RW menjadi lingkungan yang kondusif bagi terpenuhinya syarat interaksi, yaitu memberi peluang bagi terjadinya kontak dan komunikasi sosial (Carmona, et al. 2003 dan Sauter, 2008).

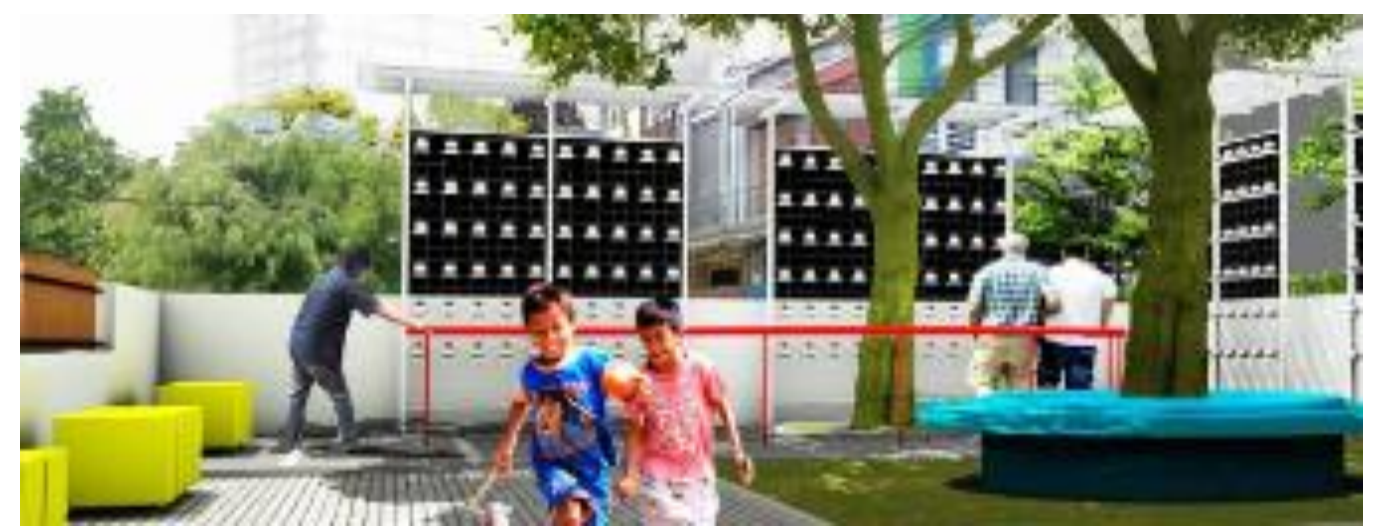

Gambar 8. Desain Taman Refleksi dan Relaksasi RW 08 (Sumber: Tim PKM, 2018)

\section{c. Bank Sampah}

Pemilahan sampah yang merupakan tahapan awal kegiatan bank sampah adalah satu kegiatan yang diwajibkan dalam masyarakat lingkungan RW (Pasal 12, Perda Provinsi DKI Jakarta Nomor 3 Tahun 2013). Sampah dipilah berdasarkan jenisnya dan dimasukkan ke dalam bak sampah yang mempunyai warna merah, kuning, dan hijau (Gambar 9).

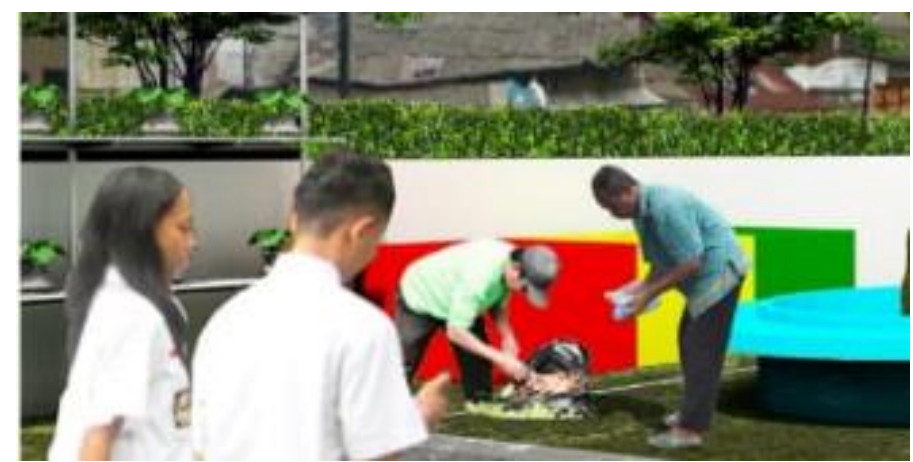

Gambar 9. Desain Bank Sampah RW 08 (Sumber: Tim PKM, 2018) 


\section{d. Tanaman Obat Keluarga (TOGA) dan Vertikultur}

Penyediaan tanaman obat di dalam area publik RW diharapkan dapat dimanfaatkan masyarakat untuk mengobati penyakit dan menjaga kesehatan (Sasmito, 2007). Dalam usulan desain, TOGA ditempatkan pada rak-rak bertingkat untuk menghemat ruang (Gambar 10). Vertikultur adalah budidaya tanaman secara vertikal di lahan yang sempit. Pada area hijau RW ditempatkan vertikultur yang berdampingan dengan area refleksi dan area TOGA (Gambar 10).

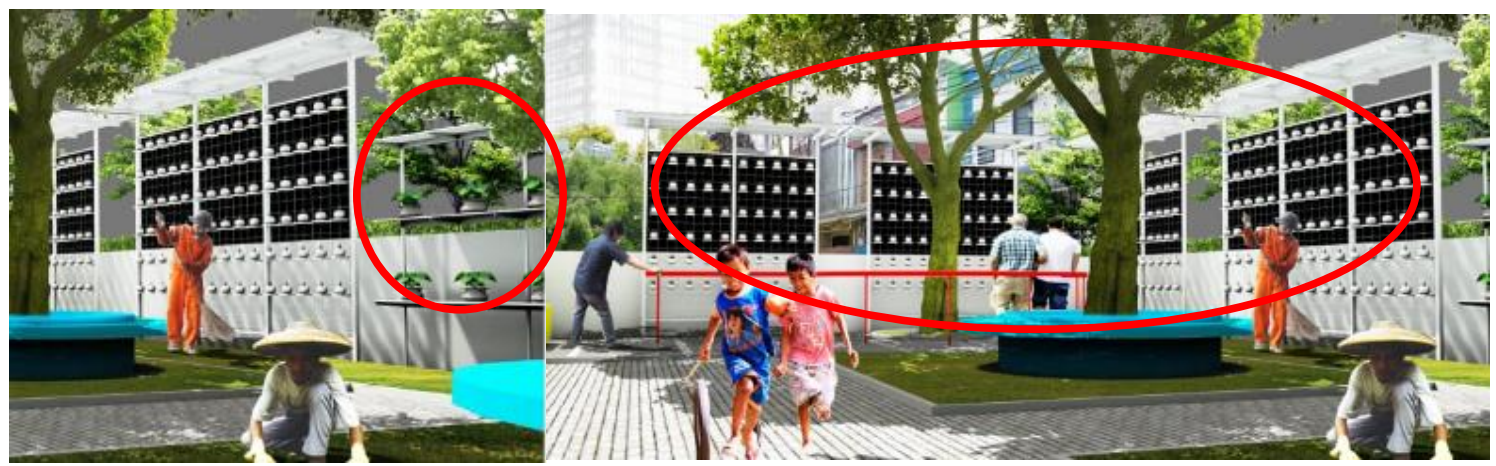

Gambar 10. Desain Toga (kiri) dan Vertikultur (kanan) yang Diusulkan

(Sumber: Tim PKM, 2018)

\section{Desain}

\section{a. Denah}

Pada rencana desain ruang terbuka tiga pohon besar tetap dipertahankan agar memberikan keteduhan dan penghujauan (Gambar 11).

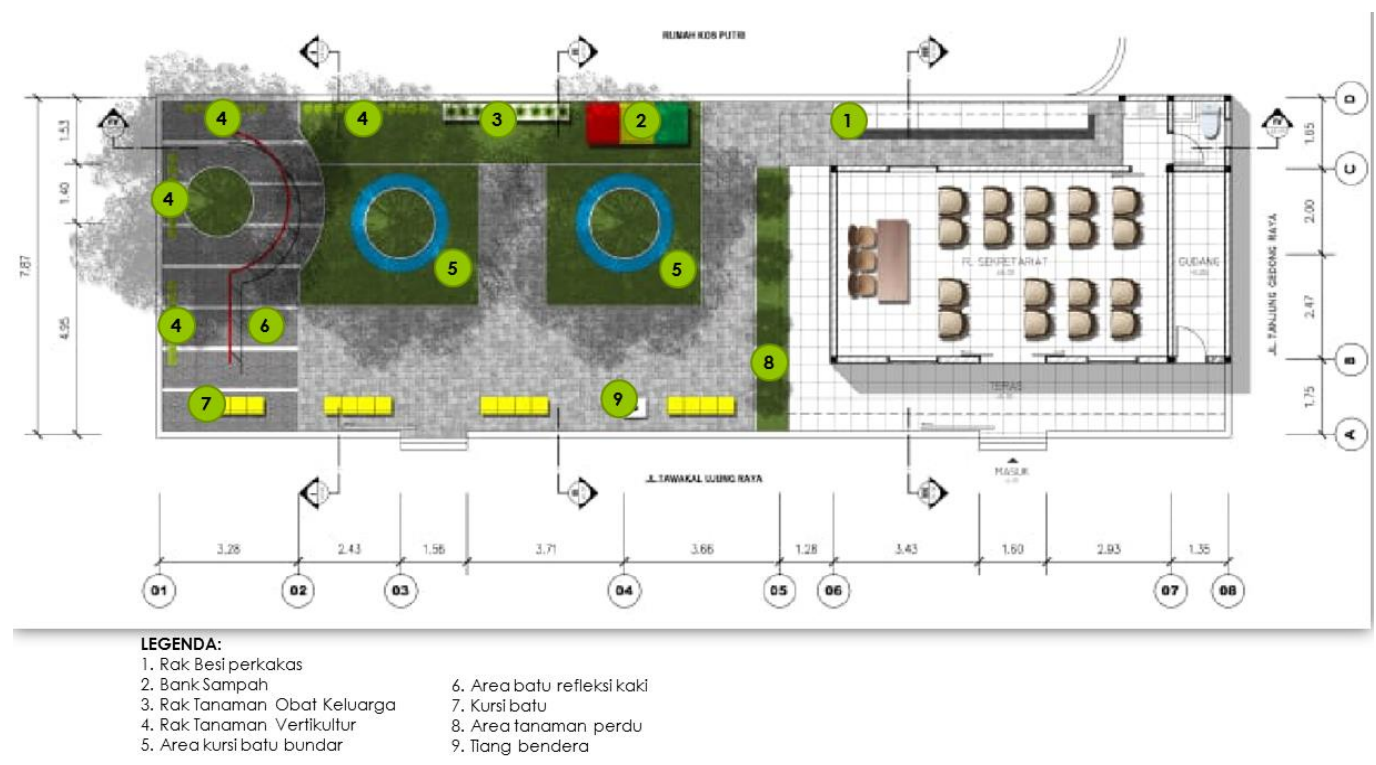

Gambar 11. Desain Denah yang Diusulkan (Sumber: Tim PKM, 2018)

\section{b. Tampak}

Pintu yang sebelumnya terletak di pinggir dipindahkan ke tengah untuk memudahkan sirkulasi dan untuk memperkuat karakter bangunan Betawi (Gambar 12). Pagar masih tetap dipertahankan karena posisi bukaan pagar sudah ada di tengah (sesuai dengan posisi pintu). 


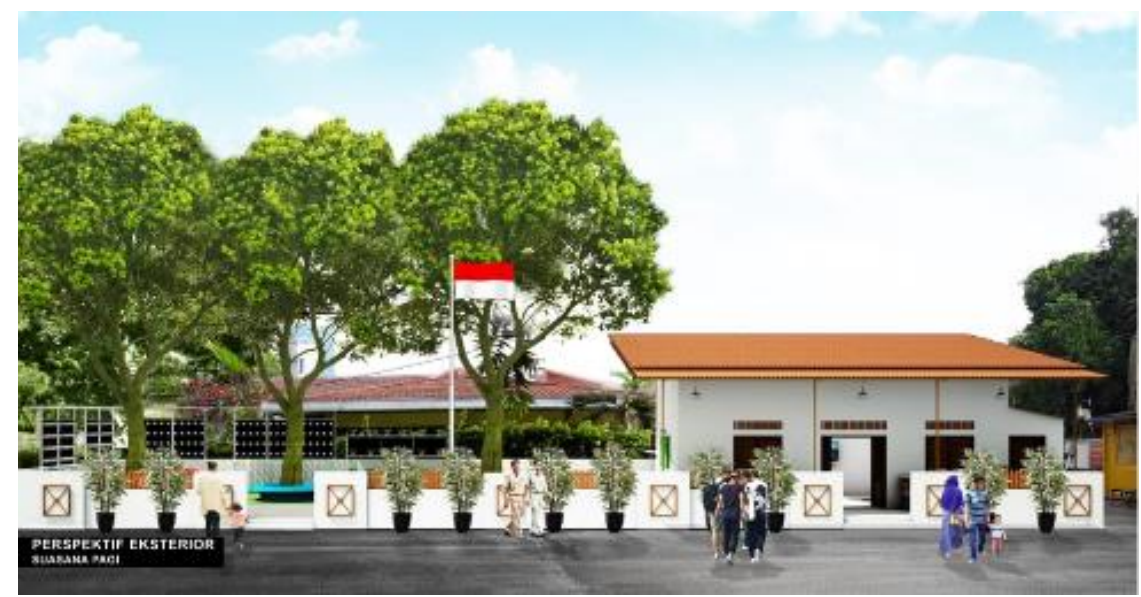

Gambar 12. Desain Tampak Depan yang Diusulkan (Sumber: Tim PKM, 2018)

\section{c. Potongan}

Perletakkan area relaksasi, vertikultur, TOGA, bak sampah, dan rak penyimpanan barang diatur sesuai dengan sirkulasi dan kebutuhan ruang. Vertikultur dan Toga ditempatkan di sekeliling pagar pembatas agar tidak mengganggu aktivitas warga untuk bermain, berolahraga, dan berkebun.
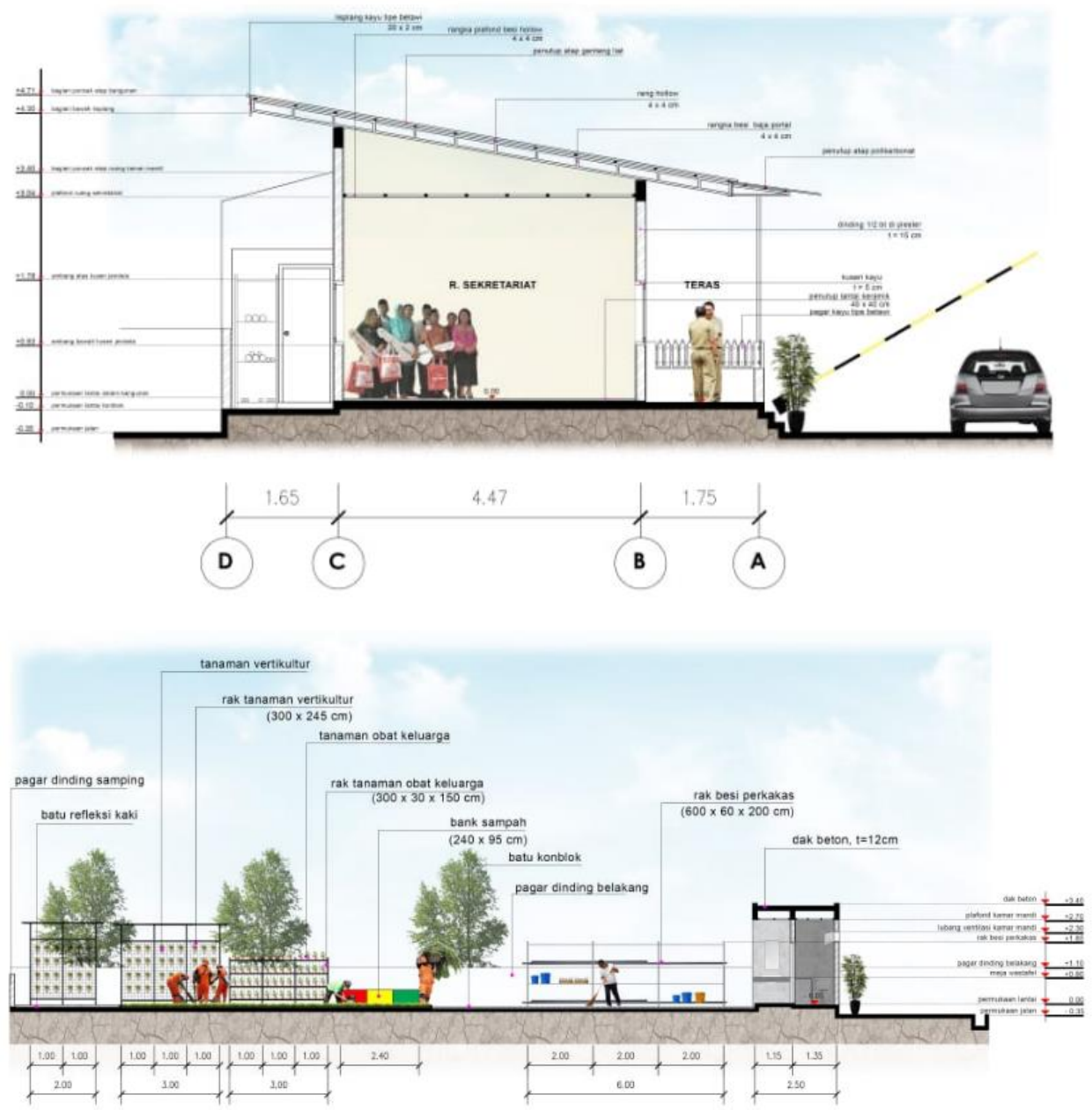

Gambar 13. Desain Potongan yang Diusulkan

(Sumber: Tim PKM, 2018) 


\section{d. Perspektif}

Desain yang diusulkan mengusung nuansa betawi menambah manfaat dari ruang publik untuk mewadahi beberapa aktivitas, antara lain: taman refleksi, TOGA, bank sampah, dan vertikultur.

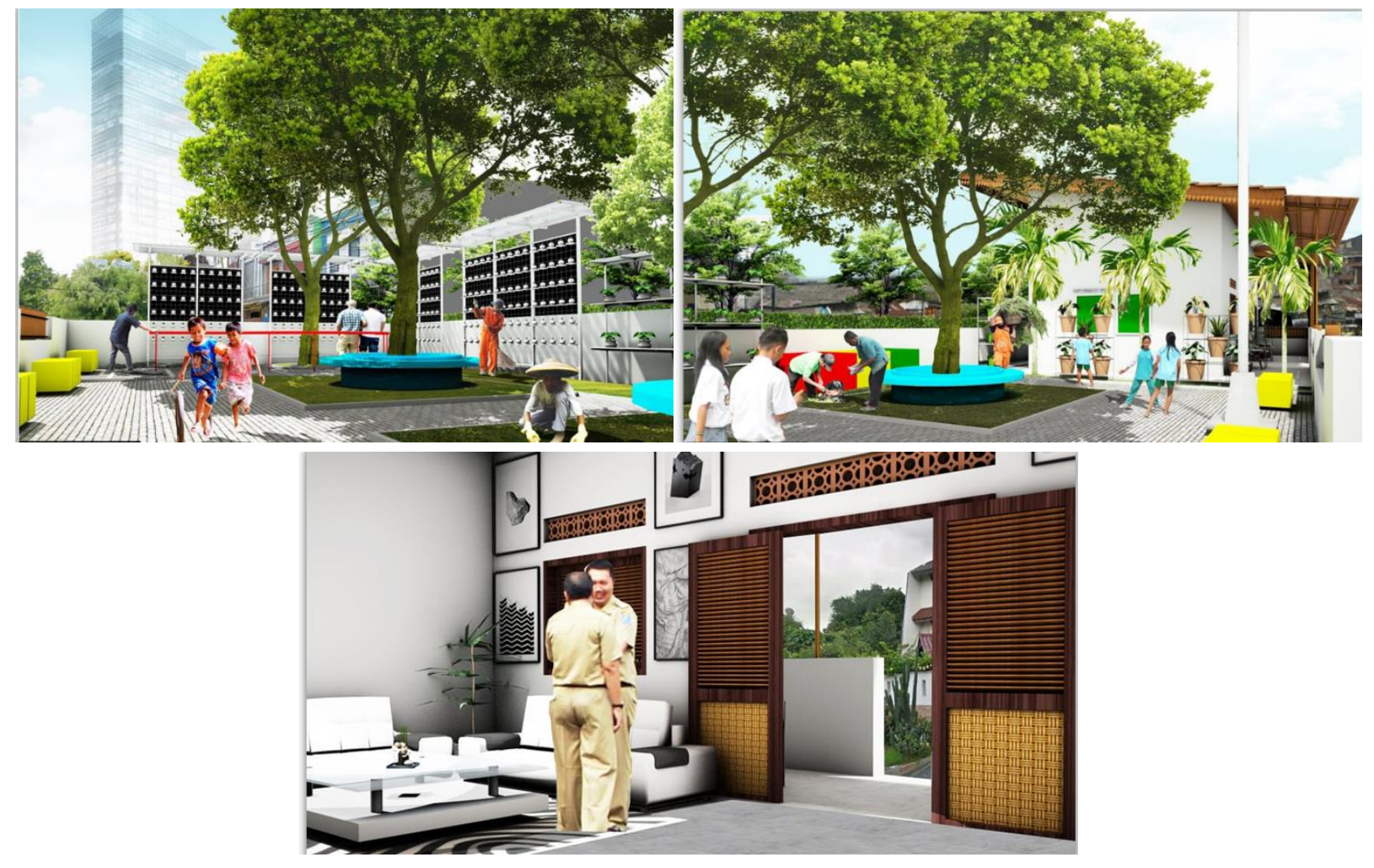

Gambar 14. Gambar Perspektif

(Sumber: Tim PKM, 2018)

\section{KESIMPULAN DAN SARAN}

Berdasarkan PKM yang telah TIM laksanakan, maka dapat diambil kesimpulan bahwa kantor Sekretariat RW.08 merupakan sebuah fasilitas yang memiliki peranan cukup penting dalam kegiatan sosial masyarakat, bukan hanya untuk kepentingan administrasi. Namun demikian, banyaknya aktivitas belum sepenuhnya diwadahi. Kantor sekretariat RW belum mengacu pada SNI 03-1733-2004 dan Perda Provinsi DKI Jakarta No. 1 Tahun 2012 dimana kantor sekretariat dan ruang publik hendaknya menjadi fasilitas penunjang yang berfungsi untuk menyelenggarakan dan mengembangkan kehidupan ekonomi, sosial dan budaya, dan memperkuat karakter wajah kota Jakarta serta menyediakan fasilitas yang memadai dan layak secara fungsional dan estetika. Konsep Desain yang diusulkan adalah: Usulan Desain Kantor Sekretariat RW yang Mencerminkan Karakter Arsitektur Betawi, pengadaan Taman Refleksi dan Relaksasi, pewadahan aktivitas Bank Sampah, usulan Taman Taman Tanaman Obat Keluarga (TOGA) dan Vertikultur.

Kantor sekretariat RW sebaiknya mampu menjadi fasilitas penunjang yang berfungsi untuk menyelenggarakan dan mengembangkan kehidupan ekonomi, sosial dan budaya, dan memperkuat karakter wajah kota Jakarta serta menyediakan fasilitas yang memadai dan layak secara fungsional dan estetika. Dalam melakukan re-desain kantor publik, harus mengacu pada standar (SNI, Perda, dll) serta harus ada diskusi aktif dengan mitra. Hal ini agar nantinya desain yang dihasilkan sesuai dengan kebutuhan mitra dan memasukkan acuan standar yang telah ada. 


\section{Ucapan Terima Kasih (Acknowledgement)}

Kami mengucapkan terima kasih atas terlaksanaya program PKM ini kepada:

1. Direktorat Penelitian dan Pengabdian Kepada Masyarakat Universitas Tarumanagara, yang telah memberikan dana PKM;

2. Bapak M. Yusuf selaku ketua RW. 08, Kelurahan Tomang sebagai mitra yang kooperatif

3. Serta kepada semua pihak yang telah membantu terlaksananya program ini.

\section{REFERENSI}

Carmona, et al. (2003). Public places - urban spaces, the dimension of urban design. Architectural press.

Carmona, et al. (2008). Public space: the management dimension. Routledge, Taylor\&Francis group. New York, USA.

Peraturan Daerah Provinsi Daerah Khusus Ibukota Jakarta Nomor 1 Tahun 2012 Tentang Rencana Tata Ruang Wilayah 2030

Pujiastuti, E. (2017). 29 Teknik Urban Farming. Jakarta: Trubus Swadaya

Sasmito, E. (2017). Imunomodulator Bahan Alami. Yogyakarta: Rapha Publishing

Sauter dan Huettenmoser. (2008). Liveable street and social inclusion. Urban design international, volume 13, 67-70. www.palgrave-journals.co.uk/udi.

Solikhah, N., et al. (2018). Re-Desain Kantor Sekretariat dan Ruang Publik RW.08, Kelurahan Tomang, Kecamatan Grogol Petamburan, Jakarta Barat. Laporan Akhir Program Kegiatan PkM, Direktorat Penelitian dan Pengabdian Kepada Masyarakat, Universitas Tarumanagara

Zhang dan Lawson. (2009). Meeting and greeting: activities in public outdoor spaces outside highdensity urban residential communities. Urban design international (2009), volume 14, 4, 207-214.

https://posyantekgropet2.wordpress.com/2015/04/16/bank-sampah-tobar-tomang-berkah/

, 2016, 40 Jenis Tanaman Obat Keluarga dan Manfaatnya. https://www.pplhpuntondo.or.id/wp-content/uploads/2017/11/40-Jenis-Tanaman-Obat-KeluargaDan-Manfaatnya-1.docx. September 3, 2016 (diakses 30 Juni 2018) 